\title{
FEDERALISMO Y AUTONOMÍAS. LA ORGANIZACIÓN TERRITORIAL DEL ESTADO EN EL CONSTITUCIONALISMO REPUBLICANO
}

\author{
ANDONI PÉREZ AYALA \\ Profesor Titular de Derecho Constitucional \\ Universidad del País Vasco
}




\section{SUMARIO}

I. El PROYeCto federal de LA I RePúblicA. 1. El movimiento republicano y el federalismo. 2. El advenimiento de la República y la opción federal. 3. La reorganización territorial y el nuevo mapa político federal. Los Estados miembros. 4. El ámbito competencial de la Federación y de los Estados miembros. 5. La organización institucional de la Federación. La reforma constitucional. 6. La caída de la República y el nuevo período político. II. LA EXPERIENCIA AUTONÓMICA DE LA II REPÚBLICA. 1. El marco político en 1931 y la cuestión de la reorganización territorial del Estado. 2. El constitucionalismo de entreguerras y la nacionalización de la organización territorial del Estado. 3. El Estado integral. 4. El marco constitucional de la autonomía regional. 4.1. El acceso a la autonomía. Los Estatutos de autonomía. 4.2. El ámbito competencial del Estado y de la autonomía regional. 4.3. El principio de igualdad y las relaciones autonómicas. 5. La organización institucional del Estado. 6. El fin de la experiencia autonómica republicana y la pervivencia del modelo autonómico. 


\title{
FEDERALISMO Y AUTONOMÍAS. LA ORGANIZACIÓN TERRITORIAL DEL ESTADO EN EL CONSTITUCIONALISMO REPUBLICANO
}

\author{
POR \\ ANDONI PÉREZ AYALA \\ Profesor Titular de Derecho Constitucional \\ Universidad del País Vasco
}

Desde su nacimiento con la Constitución de Cádiz de 1812, la configuración histórica del Estado constitucional en España, por lo que se refiere a la organización territorial del poder político, ha respondido al modelo unitario centralizado. Éste ha sido además, al menos históricamente, el modelo constitucional de referencia en Europa donde, a diferencia de los EE.UU. de América, cuyo nacimiento está asociado a la experiencia federal, la cuestión del reparto territorial del poder político apenas llega a plantearse. Tanto el constitucionalismo histórico espanol como el europeo en general aceptaron como algo natural un esquema de organización institucional del Estado basado en un único centro legislativo y ejecutivo ( $y$, por supuesto, judicial) cuyo ámbito de actuación abarca uniformemente el territorio estatal; éste, en todo caso, podrá dividirse en demarcaciones territoriales - provincias, departamentos, distritos- con el fin de facilitar el ejercicio del poder central, pero no para efectuar un reparto territorial del poder político. En líneas generales, éste ha sido el modelo de organización territorial en el Estado constitucional, tanto en España como en Europa en general desde 
su nacimiento, así como en su evolución posterior hasta épocas relativamente recientes 1 .

Tan sólo en dos momentos históricos se va a plantear la reorganización territorial del Estado constitucional en España, sobre la base del reparto y la distribución del poder político entre los entes territoriales que le integran. Serán las dos Repúblicas las que acometan esta tarea, según el modelo federal tal y como prevé el proyecto constitucional de la I República en 1873 , o el modelo autonómico en los términos que establecía la Constitución de 1931 (que habrá que completar en este último caso con los Estatutos catalán de 1932 y vasco de 1936). Si bien ambas experiencias republicanas resultaron frustradas y no representaron temporalmente mas que un breve paréntesis histórico en nuestra accidentada historia político-constitucional de los dos últimos siglos 2 , ello no debe impedir su reconocimiento como los únicos precedentes históricos de reorganización territorial del Estado. En cualquier caso, el constitucionalismo republicano quedará vinculado a esas dos experiencias históricas en las que se ensayaron formas alternativas de organización territorial del Estado.

Aunque en ambos casos había un elemento común como era el intento de reestructuración del Estado sobre la base de la redistribución territorial del poder político en favor de las entidades que le integran -Estados miembros de la Federación en 1873, Regiones autónomas en 1931 - hay que advertir también que se trata de dos experiencias que presentan características distintas, tanto por el marco político en que se desarrollaron ambos procesos bajo la I y la II República como por el modelo de organización territorial e institucional que diseñaban los textos constitucionales de 1873 y 1931. Ello obliga a hacer un tratamiento por separado de ambas experiencias republicanas: el abortado ensayo federal de la I República y las frustradas expectativas autonómicas de la II República.

1 Sobre la evolución histórica de la organización territorial del Estado en España, vid. S. Martín Retortillo y E. Argullol: «Aproximación histórica al tema de la descentralización, 1812-1931", en Descentralización administrativa y organización política, vol. I, Alfaguara, Madrid, 1973. Sobre este tema, vid., asimismo, la obra clásica de A. POSADA: La evolución legislativa del régimen local en España, 1812-1909, Librería General de Victorino Suárez, Madrid, 1910.

2 Para un estudio de ambas experiencias constitucionales republicanas en el marco del constitucionalismo histórico español, vid. F. Fernández Segado: Constituciones históricas españolas, Civitas, Madrid, 1986, pags 328-357 y 439-689. Asimismo, L. SÁnCHEz Agesta: Historia del constitucionalismo español (1808-1936), Centro de Estudios Constitucionales (CE.C), Madrid, 1984, págs. 284-292 y 459-560. 


\section{EL PROYECTO FEDERAL DE LA I REPÚBLICA}

El nuevo periodo político que se abre a partir de 1868 con el triunfo de la gloriosa revolución de Septiembre, que ponía fin a la época isabelina, va a crear las condiciones para que se plantee, por primera vez, la cuestión de la organización territorial del Estado. Los acontecimientos de Septiembre de 1868 no se limitaban a un mero cambio de gobierno tras el típico "pronunciamiento" militar sino que iban mucho más allá, proponiéndose como objetivo central la ruptura democrática con el régimen isabelino ${ }^{3}$; objetivo que se plantea abiertamente tanto en el proceso de gestación de la amplia alianza civico-militar que culminará con los acontecimientos de Septiembre de 1868 como en las proclamas de los sublevados y en los primeros Manifiestos del Gobierno provisional. Es en este nuevo escenario, marcado por el radicalismo democrático del sexenio revolucionario, en el que, en el marco de la profunda reestructuración democrática de las instituciones políticas, se van a ir abriendo paso progresivamente una serie de propuestas sobre la reorganización territorial del Estado que culminarán finalmente con el proyecto constitucional federal de la I República.

\section{El movimiento republicano y el federalismo}

Ya antes de 1868 se habian formulado algunas propuestas de corte federal; pero se trataba de propuestas de carácter puntual y esporádico que no tuvieron continuidad ni llegaron a ser incorporadas a su programa por las fuerzas políticas. De todas formas, es preciso reseñar este dato ya que es revelador de que la cuestión de la organización territorial del Estado no es un mero episodio coyuntural sino que tiene antecedentes históricos previos, muy anteriores al triunfo de la alternativa federal con la I República 4 . Pero, en cualquier caso, será en el curso del sexenio cuando van a pasar a ocupar un lugar central en el debate político llegando incluso a inspirar el proyecto constitucional republicano de 1873 , donde hallarán su plasmación expresa.

3 Además de las referencias a este periodo en los manuales y en las obras sobre la historia política del siglo XIX, cabe reseñar los números mbnográficos dedicados a este tema de la Revista de Occidente, $n .^{\circ} 67$, y Atlántida, $n .^{\circ} 36$.

4 Proyecto constitucional de R. Xauradó y Fábregas, en 1832, Bases de una Constitución política. MarX y Engels en sus escritos sobre la Revolución en España hacen referencia a un "Proyecto de Constitución de la República Federal Ibérica" en 1854. 
La cuestión de la organización territorial del Estado va a ir ganando terreno progresivamente a medida que avanza el sexenio. Aunque en los momentos iniciales éste no es un tema central para el nuevo grupo dirigente surgido de la revolución del $68^{5}$, que centrará todos sus esfuerzos en consolidar la ruptura democrática, no obstante, ya en el Manifiesto a la Nación del Gobierno Provisional (25 octubre 1868, poco más de un mes después de los acontecimientos de Septiembre) encontramos una alusión explícita a "la diversidad de orígenes y caracteres de la nacionalidad españolan, lo que no era nada usual en los documentos políticos de la época. Por otra parte, la Constitución de 1869 , sin cuestionar el caracter unitario y centralizado de la organización territorial del Estado, contiene, sin embargo, algunas alusiones a la idea de descentralización; en particular, en el terreno municipal y provincial, otorgando a los Ayuntamientos y Diputaciones la gestión, la dirección y el gobierno de los intereses municipales y provinciales (art. 37 y 99.1); asimismo, al referirse a las formas de manifestación de la vida pública, se hace una referencia a "los anchos campos de la descentralización» 6 .

Pero donde se va a plantear abiertamente el tema de la reorganización territorial del Estado sobre bases federales va a ser en el seno del movimiento republicano en gestación en estos momentos (18691873). Es más, puede afirmarse, a la vista de como se desarrolla el proceso de gestación y el nacimiento de la alternativa republicana, que la opción federal no es una, entre otras, sino que es consustancial a la propia conformación del movimiento republicano desde sus orígenes. En efecto, el proceso de formación de la estructura organizativa republicana es, a diferencia de otros partidos, un auténtico proceso federativo a partir de los grupos territoriales, cuya Federación entre si dará lugar a la estructura federal común, regida por un Consejo Federal Provisional compuesto paritariamente por representantes de las distintas federaciones territoriales (tres miembros por cada una de las cinco que

5 Ello no impide que en algunos lugares aparezcan desde el primer momento propuestas explícitamente federalistas; tal es el caso en Cataluña de V. ALMIRALL, que en 1868 da a conocer las "Bases para la Constitución Federal de la Nación española y del Estado de Cataluña" (vid. J. A. González Casanova: Federalismo y Autonomia, Ed. Crítica, Barcelona 1979, págs. 95 y ss.). En Bilbao, en los meses de 1868, la publicación de los republicanos lleva el expresivo título de "La Federación» (vid. A. Jutglar: Pi y Margall y el Federalismo español, I, Taurus, Madrid, 1975 pág. 420).

6 Dictamen de la Comisión sobre el Proyecto de Constitución (1869); vid. D. SEVILLA AndRÉs: Constituciones y otras leyes y proyectos políticos de España, l, Editora Nacional, Madrid, 1969, pág. 517. 
componen inicialmente (1869) la organización republicana)7. En ello radica la vinculación indisociable que se establece, en sus mismos orígenes fundacionales, entre el republicanismo y el federalismo.

El federalismo va a ser, por tanto, el referente común del movimiento republicano en su conjunto; pero, junto a ello, la cuestión federal va a ser también objeto de debate y de controversia en el seno del propio movimiento republicano en formación, sobre todo cuando del ideario genéricamente federalista se pasa a intentar concretar el modelo federal alternativo. Así se pone de manifiesto ya en la I Asamblea (1870) de la naciente organización republicana, en la que la orientación netamente federalista del directorio republicano (con $\mathrm{Pi} y$ Margall a la cabeza) es cuestionada por los republicanos "unitarios", quienes alertan sobre el riesgo que comportan los planteamientos del grupo dirigente para "la unidad nacional con sus naturales consecuencias de unidad de legislación, de fuero, de poder político e indivisibilidad del territorion. Estas divergencias iniciales sobre la concreción del modelo federal se reproducirán después repetidamente, bajo distintas formas, a lo largo de la evolución posterior del movimiento republicano.

Aunque el movimiento republicano no fue capaz durante este periodo inicial (1869-1872) de perfilar un proyecto federal definido $y$ compartido por el conjunto de los grupos y tendencias que se manifestaban en su seno, sí hay que reseñar, en este sentido, la aparición del primer proyecto constitucional federal, conocido como el proyecto Salmerón-Chao (principales autores del mismo) y presentado a la III Asamblea Federal republicana en 1872. Más allá del contenido del texto de este proyecto, en el que se reflejan las contradicciones que se daban en el seno del movimiento republicano en torno a la concreción del modelo federal, sí hay que llamar la atención sobre el valor que tiene al ser la primera expresión de un proyecto constitucional de organización federal del Estado9. Ello hacía posible contar, por primera vez, con

7 Sobre el proceso de formación de la organización republicana mediante pactos federativos de sus organizaciones territoriales, vid. A. JUTGLAR: Pi y Margall y el federalismo español, op. cit., pág. 426 y ss.

8 Declaración de los republicanos unitarios (7 Mayo 1870). Sobre la evolución de las diferencias entre los distintos sectores republicanos a propósito de la organización territorial del Estado, vid. G. TRUsILLo: Introducción al federalismo español, Edicusa, Madrid, 1967, págs. 169 y ss.

9 Un amplio comentario sobre este proyecto puede verse en G. TRUJILLo, Introducción al federalismo español, op. cit., pág. 180 y ss. 
un referente constitucional sobre la organización territorial del Estado de carácter federal.

\section{El advenimiento de la República y la opción federal}

El advenimiento sorpresivo de la República (11 Febrero 1873) cuando nadie preveía esa eventualidad y cuando el movimiento republicano se encontraba más debilitado a causa de su fraccionamiento, $y$ profunda división interna, va a abrir expectativas inesperadas para la alternativa republicana en general y, en este marco, para la opción federal en particular. Hay que puntualizar, sin embargo, que ambas cuestiones, la proclamación de la República, por una parte, y la definición federal de la misma, por otra, no se producen simultáneamente sino en momentos distintos del proceso preconstituyente. En cualquier caso, hay que llamar la atención también, porque ello es ilustrativo para comprender el papel que tanto la idea republicana como la federal juegan en el nuevo escenario político que se abre tras la caída de la Monarquía, sobre el hecho de que ambos pronunciamientos -el republicano y el federal- se hacen previamente a que las Cortes constituyentes republicanas inicien los trabajos sobre la elaboración y discusión del texto del proyecto constitucional ${ }^{10}$.

Tras la abdicación-dimisión de Amadeo I de Saboya, la Asamblea Nacional, compuesta por los miembros del Congreso y el Senado, "asume todos los poderes, y declara como forma de Gobierno de la Nación la República, dejando a las Cortes Constituyentes la organización de esta forma de Gobierno" ${ }^{11}$. Como puede observarse, la Declaración de la Asamblea Nacional no hace ningún pronunciamiento sobre el carácter federal o unitario de la República, ciñéndose a la estricta proclamación de ésta, sin ninguna adjetivación y sin prefigurar su estructura territorial. Por parte de los republicanos, y aunque la opción federal era una de sus señas de identidad (si bien con fuertes divergen-

10 La Declaración de las dos Cámaras - Congreso y Senado- reunidas en Asamblea Nacional, proclamando la República se hace el 11 de Febrero de 1873. La determinación del modelo de organización territorial federal se hace por las Cortes constituyentes republicanas el 7 de junio de 1873, antes de que la Comisión constitucional inicie sus trabajos. El proyecto constitucional de la República federal se presenta ante el pleno de las Cortes el 17 de julio de 1873.

11 Esta Declaración proclamando la República fue aprobada por 258 votos a favor y 32 en contra. El texto integro puede hallarse en D. SEVILLA ANDRÉs: Constituciones..., op. cit., pág. 249. 
cias entre las distintas tendencias como hemos señalado), no se llegó a formular ninguna demanda en este sentido ya que, dada la composición de la Asamblea Nacional en ese momento, no parecía lo más oportuno plantear la opción federal.

De acuerdo con la Declaración de la Asamblea Nacional proclamando la República, se reservaba expresamente a las Cortes Constituyentes la organización de ésta, incluyendo todo lo relativo a su estructura territorial. Una vez realizadas las elecciones a Cortes Constituyentes (mayo 1873), la primera decisión que van a adoptar éstas, antes incluso de iniciar las tareas constituyentes propiamente dichas de elaboración y discusión del texto del proyecto constitucional es la de determinar el modelo de organización territorial del Estado. A tal fin, fue presentada en la primera sesión plenaria de las Cortes Constituyentes una proposición de ley, de artículo único, en la que se establecía que "la forma de gobierno de la Nación española es la República democrática federal»12. No debe pasar desapercibido el hecho de que la determinación del modelo federal de organización territorial del Estado se haga previamente al inicio de los trabajos propiamente constituyentes en la comisión constitucional; ello revela la posición prioritaria, incluso desde la perspectiva temporal, que se asignaba al principio federal como elemento básico en el diseño de la nueva organización territorial republicana.

En el Informe presentado ante el pleno de las Cortes Constituyentes (17 julio 1873) por la Comisión constitucional, se pone de manifiesto, en términos no exentos de vehemencia a veces, el espíritu radicalmente federalista que inspira al constituyente republicano. Así, se alude al "amor a la localidad, que no han podido extinguir ni las violencias del absolutismo ni el recuerdo de la centralización cesarista y prefectoral»; se alude, también, al modelo federal americano: "hemos querido imitar la conducta de los grandes fundadores de la Federación en el mundo moderno", en alusión a los EE.UU.; se fija como objetivo del proyecto constitucional el establecimiento de "una división territorial que, derivada de nuestros recuerdos históricos y de nuestras diferencias, asegurase una sólida Federación, y con ella la unidad nacional". Finalmente, ante los problemas que podía plantear la compatibilidad entre los nuevos entes federativos y los tradicionales entes provinciales se adopta una posición conciliadora para alcanzar un "acuerdo prudentísimo"... "¿Sostenemos las actuales provincias? 
¿Cómo entonces fundar una verdadera Federación?¿Destruimos las provincias?... Para obviar todas estas dificultades y conciliar todos estos extremos, señalamos como nuevos Estados de la República los antiguos reinos de la Monarquía, y dejamos que los Estados por sí conserven, si quieren, las provincias o regulen a su arbitrio la más conveniente y sabia división territorial» 13 .

En esta orientación, el texto del proyecto constitucional republicano supone un profundo rediseño del esquema de organización institucional del Estado en su globalidad. Si bien la reestructuración institucional afecta al conjunto del modelo organizativo estatal, vamos a centrarnos en estas líneas en aquellos aspectos que tienen una relación más directa con la organización territorial del Estado y la redistribución del poder político en la nueva estructura federal de la República.

\section{La reorganización territorial y el nuevo mapa político federal. Los Estados miembros}

El primer problema que se le planteaba al constituyente republicano a la hora de abordar la reorganización territorial del Estado desde la perspectiva federal era la ausencia de referentes constitucionales. $\mathrm{Ni}$ en el constitucionalismo histórico español ni en el constitucionalismo europeo de la época es posible encontrar no ya un modelo de referencia sino tan siquiera criterios para el diseño de un nuevo orden federal. Tan sólo la experiencia americana, único país en el que se había consolidado de forma estable un sistema constitucional federal, podía proporcionar elementos al constituyente republicano en 1873 para emprender la tarea de federalización del Estado; pero, a diferencia de los modelos constitucionales europeos, más afines al nuestro, el modelo americano resultaba más lejano, no sólo geográficamente sino, sobre todo, por los principios y la estructura del orden jurídico-constitucional, que difieren sensiblemente del nuestro (así como del europeo, en general) ${ }^{14}$. Ello obligaba al constituyente republicano a hacer un esfuerzo

13 El texto íntegro del Informe de la Comisión constitucional, muy importante para conocer el pensamiento del constituyente republicano, puede hallarse en D. SeVILla Andrés: Constituciones..., op. cit., pág. 555.

14 A pesar de todo, la influencia del modelo constitucional americano fue notoria, tanto en lo relativo al federalismo en particular como en la filosofía política del constitucionalismo del sexenio en general. Vid. En este sentido, J. OLtRA: La influencia norteamericana en la Constitución española de 1869, Instituto de Estudios Administrativos, Madrid, 1972, pág. 109. 
de innovación constitucional en este terreno, no sólo en relación con nuestro constitucionalismo histórico sino también con el constitucionalismo europeo de la época.

El proyecto constitucional republicano establece un nuevo mapa político, basado en entidades territoriales diferentes a las existentes hasta el momento - las provincias - y vinculadas entre sí por medio de relaciones federativas - los Estados miembros de la Federación-. Se trata, en cierta forma, de una refundación del Estado, al menos por lo que se refiere a las entidades territoriales que lo integran. En efecto, el Estado federado se distingue de otros entes territoriales, en particular de las provincias, no sólo por el ámbito territorial de extensión, que puede incluso llegar a coincidir en algunos casos (así, por ej. Asturias o Navarra) sino, sobre todo, por la naturaleza jurídico-política de ambos entes - provincias y Estados miembros de la Federación-y por el lugar que ocupan en la estructura federal. Interesa reseñar que al determinar los Estados miembros de la Federación (art. 1), el constituyente republicano intenta reflejar la pluralidad territorial tal y como se ha manifestado históricamente 15.

La reorganización territorial del Estado sobre la base de los Estados federados, que constituyen el elemento estructural básico del nuevo modelo de organización (federal) de la República, es compatible, sin embargo, con la flexibilidad que muestra el constituyente republicano con el tratamiento de los entes provinciales. En este sentido, es preciso observar que en la misma disposición constitucional en la que se constitucionalizan los Estados miembros de la Federación se faculta a éstos para "conservar las actuales provincias o modificarlas, según las necesidades territoriales" (art. 1). Se trata, sin duda, de una previsión prudente - "arreglo prudentísimo" es la expresión literal que se emplea en el Informe de la Comisión Constitucional, ver supra- que tiene en cuenta la diversidad de situaciones que pueden darse en el seno de los diversos Estados de la Federación; desde aquellas en las que hay entidades distintas de la provincia con fuerte arraigo (por ej.: las comarcas; especialmente en Cataluña y Valencia), hasta aquellas en las que la provincia se ha consolidado como entidad territorial; o, por último aquellas en las que en la misma demarcación

15 En el Informe de la Comisión constitucional se alude expresamente a los "antiguos reinos de la Monarquía" como la base sobre la que se configuran "los nuevos Estados de la República». Cfr. D. Sevilla Andrés: Constituciones..., op. cit., pág. 556. 
territorial de ámbito provincial se superpone otra entidad de naturaleza diferente ${ }^{16}$.

Hay que reseñar, por último el hecho de que el nuevo mapa político diseñado por el constituyente republicano de 1873 es, con algunas modificaciones, el actual mapa autonómico. No deja de ser altamente significativo este dato histórico ya que muestra como el proyecto constitucional republicano de 1873 prefiguró, con más de un siglo de antelación, un mapa político-territorial muy similar al que hoy rige en el Estado autonómico actual17. Ello revela, por otra parte, además de la perspicacia histórica del constituyente republicano, la continuidad de la constitución territorial en sus elementos estructurales básicos, que no experimentarán cambios sustanciales durante más de un siglo.

\section{El ámbito competencial de la Federación y de los Estados miembros}

El reparto de poderes entre la Federación y los Estados miembros, tema clave en todo Estado federal, es abordado en el proyecto constitucional republicano según el esquema del modelo constitucional americano, que en ésta como en otras muchas materias le sirvió de referente. De acuerdo con él, el ámbito competencial federal se determina en una lista única, en la que se enumeran las materias que corresponden a los Poderes públicos de la Federación (Tít. V, art. innumerado entre el 49 y 50). Se trata de una lista extensa (23 números) que, a pesar de la escasa sistemática de que adolece, nos proporciona un criterio referencial para conocer la posición del constituyente republicano en lo relativo al área de poder reservada en exclusiva a los órganos federales.

Sin entrar en un análisis detallado del contenido de esta disposición constitucional, que de haber tenido ocasión de ser debatida en el pleno de las Cortes Constituyentes hubiese sido, sin duda, ordenada

16 Es el caso, por ejemplo, de lo que hoy se denomina Territorios Históricos en el País Vasco, que el proyecto constitucional republicano conocía bajo la denominación de "Regiones Vascongadas" (art. 1).

17 El nuevo mapa político que establecía el proyecto constitucional republicano (art. 1) estaba integrado por "los Estados de Andalucía Alta, Andalucía Baja, Aragón, Asturias, Baleares, Canarias, Castilla la Nueva, Castilla la Vieja, Cataluña, Cuba, Extremadura, Galicia, Murcia, Navarra, Puerto Rico, Valencia y Regiones Vascongadas". Obsérvese la similitud con el actual mapa autonómico. 
más sistemáticamente y perfilada con mayor precisión 18 , se pueden distinguir en ella cinco grandes bloques competenciales de la Federación: relaciones internacionales; defensa; infraestructuras comunes básicas, áreas reservadas prácticamente en su integridad a la competencia exclusiva de los órganos federales; en el área de interior cabe mencionar, entre otras, el mantenimiento de la unidad e integridad nacional y uel arreglo de las cuestiones territoriales y de las competencias entre los Estados"; por último, en el área económica, la moneda, la deuda y los empréstitos nacionales, aduanas y aranceles y todo lo relacionado con "las contribuciones y rentas que sean necesarias para el mantenimiento de los servicios federales". Se echa en falta, junto al listado de competencias expresas de la Federación, una cláusula similar a la de los poderes implícitos de la Constitución americana (art. 1, sec. 8, . $^{\circ} 18$ ), lo que resulta más llamativo si se tiene en cuenta que el modelo federal americano fue el referente del constituyente republicano de 1873.

Esta disposición constitucional relativa a los poderes de la Federación (Tít. V) ha de ser completada necesariamente con las disposiciones relativas a los Estados miembros (Tít. XIII, arts. 92-105). La combinación de ambas, así como también de las disposiciones de las Constituciones de los Estados miembros (que no llegaron a ver la luz en ningún caso) nos proporciona el marco global de la distribución de poderes entre la Federación y los Estados miembros ${ }^{19}$.

Por lo que se refiere a estos últimos, la disposición del proyecto constitucional con la que se abre este Título (art. 92) atribuye a los Estados "completa autonomía económico-administrativa y toda la autonomía política compatible con la existencia de la Nación". Asímismo, se reconoce a los Estados "la facultad de darse una Constitución política» con la única condición de que no entre en contradicción con la Constitución federal (art. 93). Se trata, como se deduce del enunciado de las disposiciones constitucionales precitadas, de un ámbito competencial que, además de su amplitud en favor de los Estados miembros -los únicos límites, de carácter muy genérico, los establece la propia

18 Por la forma en que está redactada y ubicada esta disposición constitucional, que presenta la particularidad de no estar numerada, todo parece indicar que más de un artículo del proyecto en sentido estricto, el constituyente la concibió como un guión abierto para su posterior discusión.

19 Para un tratamiento más amplio sobre esta cuestión, que no es posible desarrollar aquí, remito al lector a mi trabajo "La I República. Marco político y proyecto constitucional", Revista de Estudios Políticos, n. ${ }^{\circ} 105,1999$, pág. 55 y ss. 
"existencia de la Nación" y la Constitución federal- responde al esquema típicamente federal de distribución de poderes, de acuerdo con lo que dispongan los respectivos textos constitucionales, federal y de los Estados miembros.

Si bien las Constituciones de los Estados miembros no llegaron a aprobarse en ningún caso, lo que nos priva de conocer con precisión las materias concretas que integraban su propio ámbito competencial, sí es posible, sin embargo, conocer el marco de referencia en el que quedaban encuadradas a través de las disposiciones del proyecto constitucional relativas a los Estados (Tít. XIII). Así, por ejemplo, se reserva a los Estados un amplio bloque competencial en materia de fomento: "regirán su política propia, su industria, su hacienda, sus obras públicas, sus caminos regionales, su beneficencia, su instrucción» (art. 96), añadiendo a esta relación de materias una cláusula final de suma importancia que extiende el ámbito competencial de los Estados a "todos los asuntos civiles y sociales que no hayan sido remitidos por esta Constitución al poder federaln. Se trata en este último caso de la cláusula de los poderes residuales, que opera en favor de la extensión del ámbito competencial de los Estados miembros y que ha sido clave para la delimitación de éste como lo pone de relieve la experiencia federal americana20.

Además de las disposiciones precitadas en las que se establece el marco general del ámbito competencial de los Estados miembros, el proyecto constitucional hace referencia a materias especificas atribuidas a la competencia de estos últimos: en cuanto a su propia organización interna, "la regularán a su arbitrio y bajo sus expensas" (art. 100); en el terreno económico-financiero "podrán levantar empréstitos y emitir deuda pública para promover su prosperidad interior" (art. 97); en materia de orden público se faculta a los Estados para disponer de su propia fuerza pública, aunque en este caso hay que puntualizar que se hace en términos limitativos: «los Estados no podrán mantener más fuerza pública que la necesaria para su policía y seguridad interior» precisando a continuación que «la paz general de los Estados se halla

20 La jurisprudencia del Tribunal Supremo USA ha sido decisiva para delimitar el alcance de la cláusula de los poderes residuales, así como también la de poderes implícitos y la de supremacía, en las que se basa la distribución de poderes entre la Unión y los Estados miembros. Vid. Al respecto M. Garcia Pelayo: Derecho Constitucional Comparado, Alianza Universidad, Madrid, 1984; en particular el Capítulo dedicado al "Derecho Constitucional de los Estados Unidos", págs. 355, 361 v 363. 
garantizada por la Federación, y los poderes federales podrán distribuir la fuerza nacional a su arbitrio, sin necesidad de pedir consentimiento alguno a los Estados" (art. 101).

Especial interés tiene la disposición constitucional relativa a la enseñanza secundaria y superior por la que se impone a los Estados "la obligación de mantener un Instituto de segunda enseñanza por cada una de las actuales provincias y la facultad de fundar las Universidades y Escuelas especiales que estimen conveniente». Hay que llamar la atención sobre el alcance y la singularidad de esta previsión constitucional (en 1873!), sin duda pionera del constitucionalismo social en el campo educativo. Interesa observar que se trata de un mandato constitucional expreso dirigido a los poderes públicos - de los Estados miembros en este caso-que comporta una obligación para éstos y no, como suele ser usual, meras orientaciones o principios genéricos para promover la cultura y la educación.

Por último, y dentro del Título que comentamos relativo a los Estados (Tít. XIII), el constituyente republicano no se olvida de precisar que ulos ciudadanos de cada Estado gozarán de todos los derechos unidos al título de ciudadano en todos los otros Estados" (art. 103), constitucionalizando así expresamente el principio de ciudadanía común para todos los ciudadanos de la República. La formulación explícita de este principio, sin el cual la Federación se diluiría, establece el fundamento básico del orden constitucional federal, concretado en el vínculo ciudadano común21. Por otra parte, sirve también para fundamentar las cláusulas prohibitivas a los Estados (así como a cualquier órgano de la Federación), que no podrán adoptar medida alguna que atente contra los derechos ciudadanos (art. 99).

\section{La organización institucional de la Federación}

El nuevo modelo de organización territorial del Estado de acuerdo con el esquema federal va a repercutir inevitablemente en la configuración de los órganos comunes de la Federación. Si bien todos ellos se van a ver afectados por la reorganización institucional, ésta dejará sentir sus efectos de forma especial sobre el Senado y el Tribunal Su-

21 El principio de ciudadanía común se halla constitucionalizado bajo formas diversas en todas las Constituciones federales: art. 6 de la Constitución austriaca; art. 8 de la Constitución belga; arts. 16 y 116 de la Constitución alemana; art. 43 de la Constitución suiza... 
premo, que experimentarán una remodelación sustancial en cuanto a su composición y a las nuevas funciones que se les va a asignar.

El proyecto constitucional mantiene el bicameralismo que, con la excepción de la Constitución de Cadiz (y más tarde, como veremos, la Constitución de 1931), ha sido el modelo vigente en nuestro constitucionalismo histórico. Pero la configuración del Senado en el proyecto constitucional de 1873 difiere por completo de la que tenía hasta entonces y tendrá después - adoptando un perfil distinto como Cámara de representación de los Estados miembros de la Federación. De acuerdo con este nuevo esquema, variará sustancialmente su composición y la forma de elección de los senadores: cada Estado miembro estará representado por cuatro senadores, "cualquiera que sea su importancia y el número de sus habitantes" (art. 52), que serán elegidos por las Asambleas parlamentarias de sus respectivos Estados. Esta configuración del Senado responde plenamente al modelo federal clásico 22 , basado en la representación paritaria de los Estados miembros y en la elección de los senadores a través de sus propios órganos representativos.

No se puede afirmar lo mismo, sin embargo, por lo que se refiere a las funciones que se le asignan al Senado, que difieren sensiblemente de las que son inherentes a un Senado propiamente federal. En este sentido, hay que decir que el proyecto constitucional (Tít. VIII, art. 70) configura un Senado devaluado, en una posición secundaria en relación con la otra Cámara, el Congreso, que será la que ostente el protagonismo principal. Ello se pone especialmente de manifiesto en el terreno legislativo, en el que el Senado, además de carecer de iniciativa legislativa como precisa de forma expresa el propio texto del proyecto (art. 70), ve limitadas sus funciones a un cierto control de la actividad legislativa del Congreso; en concreto, se ocupará "exclusivamente", según se puntualiza en la referida disposición constitucional, de «examinar si las leyes del Congreso desconocen los derechos de la personalidad humana, o los poderes de los organismos políticos, o las facultades de la Federación, o el Código fundamental»23. Hay que añadir, además, que ni siquiera en estas materias el Senado tiene facultades

22 En particular al modelo federal americano, en el que los senadores (dos por cada Estado) eran elegidos por las legislaturas de los Estados miembros. Posteriormente, a partir de 1913 (XIII Enmienda) pasarán a ser elegidos directamente por el electorado de cada Estado.

23 F. Fernández Segado (Constituciones históricas..., op. cit. pág. 349) habla de " un cierto control de legalidad, distinto por supuesto del control de constitucionalidad que preveía el art. 77 " (este último artículo se refiere a la suspensión de los efectos de una ley contraria a la Constitución por el Tribunal Supremo Federal). 
decisorias sino tan sólo un veto suspensivo temporal que no impide que la ley en cuestión sea finalmente aprobada si el Congreso insiste en ello por tercera vez en el plazo de tres años.

Se trata, en definitiva, de una configuración muy defectuosa del Senado desde el punto de vista federal, al que ni siquiera se le asignan funciones especificas en materia de organización territorial, y que no deja de sorprender teniendo en cuenta el influjo que ejerció sobre el constituyente republicano de 1873 el modelo federal americano, en el que el Senado responde a un diseño diferente.

Otro órgano que también va a verse afectado por la reorganización territorial del Estado es la más alta instancia jurisdiccional, que incluso va a cambiar su denominación para hacer referencia expresa a su carácter federal: Tribunal Supremo Federal. La composición de este órgano experimentará un importante cambio, pasando a ser elegidos sus miembros según criterios estrictamente paritarios: "se compondrá de tres magistrados por cada Estado de la Federación" (art. 73), quienes, a su vez, elegirán, entre ellos, al Presidente (art. 74). No se dice nada sobre la forma de elección ni sobre las condiciones que deben reunir los elegidos, remitiendo estas cuestiones a la correspondiente legislación de desarrollo constitucional sobre la materia, que no llegó a aprobarse. En cualquier caso, se trata de unos criterios discutibles, como han puesto de relieve los comentarios doctrinales al respecto 24 , no tanto por la intención que les anima -el equilibrio territorial- como por la rigidez con la que aborda la cuestión ya que se hace de la paridad entre los representantes territoriales el único criterio a tener en cuenta para la composición del T.S.F.

Independientemente de las importantes funciones que el proyecto constitucional asigna al T.S.F. en materia de control de constitucionalidad de las leyes - tema que no podemos tratar aquí por razones, entre otras, de espacio ya que, dada su entidad, será preciso dedicarle un amplio capítulo25 - y ciñéndonos exclusivamente a aquellas funciones relacionadas directamente con la organización territorial del Estado, hay que decir que el T.S.F. ocupa un lugar clave en la estructura ins-

24 Vid. E. Llorens, para quien "cuanto mayor sea la importancia que se atribuya a la procedencia territorial de los jueces, menor es la confianza en la imparcialidad del Tribunal", La autonomía en la integración política, Madrid, 1932, pág. 283.

25 Vid. al respecto, S. A. Roura: La defensa de la Constitución en la historia constitucional española, Centro de Estudios Políticos y Constitucionales, Madrid, 1998 , pág. 226 y ss. 
titucional federal ya que a él compete entender y decidir sobre los litigios entre los Estados miembros (art. 78), quienes "tendrán que someter sus diferencias a la jurisdicción del Tribunal Supremo Federal»" (art. 101); asimismo, recaen también bajo la jurisdicción del T.S.F. los conflictos «en los que la Nación sea parte» (art. 79) y "el arreglo de las cuestiones territoriales" (art. innumerado del Tít. V, n. ${ }^{\circ} 4$ ). En definitiva, el T.S.F., además de la más alta instancia jurisdiccional en las cuestiones judiciales ordinarias y de tener asignada la nueva e importante función ya señalada del control de la constitucionalidad de las leyes, se erige en el órgano clave para la resolución de los conflictos derivados de la organización territorial del Estado. Hay que advertir, no obstante, que estas previsiones constitucionales no tuvieron aplicación en la practica ya que el T.S.F. no llegó a constituirse efectivamente, lo que nos impide hacer una evaluación del papel que hubiera podido jugar realmente en la estructura institucional federal.

Por lo que se refiere al ejecutivo, el proyecto constitucional sólo hace referencia a una función especifica en relación con la organización territorial: "enviar a cada Estado regional un delegado con encargo expreso de vigilar el cumplimiento de la Constitución y de las leyes, de los decretos y reglamentos federales" (art. $72.8 .^{\circ}$ ) precisando a continuación que carecerá de "autoridad ninguna especial dentro del Estado o del Municipion. El Delegado del Gobierno puede ser caracterizado, según se desprende de estas palabras, como un observador que deberá informar al Gobierno, en el supuesto de que advierta una vulneración de la legalidad federal, para que éste adopte las medidas oportunas.

Por lo que se refiere al Presidente de la República Federal, figura que en el proyecto constitucional está claramente separada del ejecutivo y que es objeto de un tratamiento diferenciado, se le asigna, en relación con la organización territorial, la función específica de "cuidar que sean garantizadas las Constituciones particulares de los Estados» (art. 82.10. ${ }^{\circ}$. Si bien más que una función específica ha de ser considerado como algo consubstancial al cargo presidencial, extensible además a la Constitución y a las leyes federales, esta alusión explícita a las Constituciones de los Estados miembros puede ser interpretada corno una muestra de la sensibilidad federalista del constituyente republicano.

Finalmente, en lo que atañe a la reforma constitucional, hay que llamar la atención sobre el nulo papel que se reserva a los Estados miembros de la Federación en el proceso de revisión constitucional. Se trata de una importante laguna que, al menos desde una 
perspectiva federal (que era en la que se situaba el constituyente republicano) debe merecer un juicio muy crítico por su olvido de un elemento básico en todo régimen federal como es la participación de los Estados miembros en toda medida que pueda afectar a su propio status en la Federación; y con mayor razón aun si se trata nada menos que de la modificación del marco constitucional común ${ }^{26}$. Quizás pueda servir como explicación de esta grave omisión el hecho de que, en este punto, el constituyente republicano se limita a transcribir literalmente la disposición constitucional relativa a la reforma constitucional de la Constitución de 1869 , en la que no se preveía ningún modelo federal sobre la organización territorial del Estado. Previsiblemente, en el caso de que se hubiese tenido oportunidad de debatir sobre esta cuestión en el Pleno de las Cortes Constituyentes, se hubiera reformulado en otros términos más acordes con el espíritu federal. Pero ello no fue posible ya que, como es sabido, las Cortes Constituyentes fueron disueltas por un acto de fuerza el 3 de Enero de 1874 , antes de haber podido discutir el proyecto constitucional de la República federal.

\section{La caída de la I República y el nuevo período político}

La caída de la I República, sin haber llegado a cumplir siquiera su primer año de vida, supone al mismo tiempo la frustración de la alternativa federal, a la que estaba estrechamente vinculada, como hemos podido observar al examinar su proceso de gestación y nacimiento. No hay que olvidar, por otra parte, que la instauración de la República no fue el resultado de una victoria de los republicanos sino la consecuencia del vacío político que se produjo tras la abdicación sorpresiva del monarca, Amadeo I de Saboya, y el agotamiento de la fórmula monárquica, precisamente en el momento en que el movimiento republicano estaba más debilitado como consecuencia de su división interna. Asimismo, el modelo federal que diseñaba el proyecto constitucional de 1873 tampoco era el producto del auge y de la fuerza de una potente corriente federalista con capacidad para aglutinar no ya a una amplia mayoría social sino tan siquiera a la propia "clase política" de la épo-

26 El procedimiento de revisión constitucional se aparta sensiblemente del modelo americano, en el que los Estados miembros participan en el proceso de revisión, $y$ está inspirado en el procedimiento que establecía en aquel momento la Constitución belga de 1831 (art. 131), que fue el que recogió la Constitución española de 1869. 
ca; tan sólo una pequeña fracción de ésta, sobrerrepresentada institucionalmente a causa del retraimiento del resto de las fuerzas políticas en la especial coyuntura política posmonárquica de 1873, se decantaba claramente por la opción federal27. A todo ello hay que añadir la accidentada, conflictiva, y a veces hasta caótica situación que se vivió durante la breve experiencia republicana, lo que no contribuía precisamente a generar apoyos en favor de la causa republicana y federal.

En estas condiciones, no es de extrañar que se produjese la quiebra de la I República, antes incluso de que pudiera empezar a funcionar el sistema institucional —incluida la reorganización federal- prevista en el proyecto constitucional, que no llegó siquiera a ser aprobado por las Cortes Constituyentes (y al que por tanto, dicho sea de paso, no se le puede imputar la situación de aguda crisis política que se desarrolló en 1873). Después de la caída de la República, el movimiento republicano va a sufrir un proceso de fraccionamiento $y$ de dispersión que se agravará progresivamente a medida que se va asentando y consolidando el régimen político de la Restauración ${ }^{28}$. Hay un dato, sin embargo, en este proceso que merece especial atención para nosotros a los efectos del tema que nos ocupa, como es la desvinculación que se va a producir, y que será creciente a medida que avanza este periodo, entre el republicanismo y el federalismo, ideas que habían sido indisociables desde el periodo fundacional del movimiento republicano-federal. Ello se pondrá claramente de manifiesto, como veremos a continuación, cuando tras el dilatado periodo de la Restauración se plantee nuevamente la alternativa republicana en 1931; pero en este momento, los partidarios de la opción federal serán tan sólo una pequeña fracción en el conjunto de las fuerzas republicanas.

En cualquier caso, e independientemente de la contradictoria experiencia republicana de 1873 , hay que decir que fue en este marco en el que se planteó, por primera vez, la cuestión de la reorganización territorial del Estado sobre la base de un modelo alternativo —en este ca-

27 A pesar de que en las elecciones constituyentes de mayo de 1873 las candidaturas republicanas obtienen una aplastante mayoría (343 escaños sobre 391) se trataba de una mayoría engañosa ya que la abstención electoral fue altísima: hubo zonas, como el País Vasco, donde alcanzó el $85 \%$ (Datos aportados por M. Martínez Cuadrado: Elecciones y partidos políticos en España, 1868-1931, Taurus, Madrid, 1969; y F. Fernández Segado: Constituciones históricas..., op. cit., pág. 333).

28 Sobre la evolución del movimiento republicano federal después de 1874, vid. A. JutglaR: Pi y Margall y el federalismo español, II; en particular, la «Parte Quinta: Los intentos de reorganización y el fracaso del federalismo pimargalliano", pág. 617 y ss. 
so, el federa - al del Estado unitario y centralizado29. Una cuestión que no fue meramente coyuntural ni producto de la imaginación aventurera de los republicanos de 1873 (como a veces se ha llegado a decir con ligereza) sino que se trata, por el contrario, de un problema estructural del Estado español que volverá a replantearse, si bien bajo formas distintas, cada vez que se abra un proceso de transición democrática, como ocurrió después en 1931 ( $y$ también en 1977-78). En este marco histórico, la I República, y en concreto su proyecto constitucional federal, representa el intento pionero de dar solución a este problema, aún no resuelto definitivamente, de la organización territorial del Estado.

\section{LA EXPERIENCIA AUTÓNOMICA DE LA II REPÚBLICA}

En el momento en el que se instaura la II República, la cuestión de la organización territorial del Estado vuelve a plantearse de nuevo. Junto con la cuestión social y la religiosa son los tres problemas principales a los que va a tener que hacer frente el constituyente republicano ${ }^{30}$. Pero en 1931, la entonces denominada cuestión regional se va a plantear de forma distinta a cómo lo fue casi seis décadas antes, durante la fugaz experiencia federal de la I República.

\section{El marco político en $\mathbf{1 9 3 1}$ y la cuestión de la organización territorial del Estado}

En primer lugar, los republicanos de 1931 no tienen, a diferencia de los de 1873, al federalismo como modelo de referencia para la futura organización territorial del Estado. Durante el largo periodo que media entre la caída de la I República y la instauración de la segunda, la alternativa federal va dejando de ser un elemento común de identificación para los republicanos, cuyo fraccionamiento y dispersión será creciente a medida que avanza el periodo de la Restauración. Si bien en los primeros años (hasta la última década del siglo XIX) la referencia

29 Sobre los planteamientos ideológicos del federalismo republicano, vid. G. TRUJILLo: Introducción al federalismo..., op. cit; en particular, el capítulo dedicado a "Los fundamentos ideológicos del federalismo español", pág. 89 y ss.

30 Todos los autores coinciden en señalar estas cuestiones como las más problemáticas durante la II República. Cfr., entre otros, J. TomÁs VILLARROYA, en su excelente síntesis histórico-constitucional Breve historia del constitucionalismo español, CEC, Madrid 1997, págs. 124 y ss.. Algunos tratadistas añaden también a éstas la cuestión agraria y la cuestión militar. 
federal sigue viva en sectores importantes del movimiento republicano, progresivamente irá perdiendo peso. Por otra parte, la desaparición física de los principales líderes vinculados directamente a la experiencia republicana de $1873^{31}$, sin que sus sucesores asuman la continuidad del proyecto federal, contribuirá de forma decisiva a la progresiva difuminación de éste. Así pues, en 1931, el peso de la opción federal en el propio seno del movimiento republicano, al que estaba vinculada desde su nacimiento, era sumamente limitado.

Por lo que se refiere al resto de las fuerzas políticas, menos aún es posible hallar en ninguna de ellas planteamientos de signo federal. En el caso de los partidos que se turnaban en el gobierno, y sobre los que se asentó el orden político de la Restauración, las razones son obvias ya que el tradicional modelo unitario y centralizado de organización territorial del Estado era asumido como algo natural sin plantearse siquiera su cuestionamiento o su remodelación en ningún momento ${ }^{32}$. En el caso del PSOE, nueva formación política que hace su aparición en este periodo y que irá ganando un protagonismo creciente hasta convertirse, junto con los republicanos, en una de las fuerzas políticas clave de la II República, la cuestión es más compleja pero, en cualquier caso, no puede decirse que los planteamientos federales fuesen un elemento determinante en su proyecto político. No se trataba de un rechazo de éstos en favor del modelo tradicional sino, simplemente, de que las preocupaciones prioritarias de los dirigentes socialistas en 1931 se centraban en torno a otros temas ${ }^{33}$. Consideraciones similares cabe hacer sobre la otra fuerza política de la izquierda, el PCE, a lo que hay que añadir en este caso que por la fecha de su nacimiento (1921) y la precaria situación de clandestinidad en la que tuvo que vivir desde 1923, apenas tuvo tiempo materialmente de perfilar una alternativa elaborada sobre la organización territorial del Estado34.

31 Figueras muere en 1882; Ruiz Zorrilla en 1895; Castelar en 1899; Pi y Margall en 1901; Salmerón en 1908. Con ellos se extinguía la generación republicana de 1873.

32 Cfr. M. Espadas Burgos: "Centralismo y regionalismo en la época de la Restauración", en AA.VV.: Centralismo y descentralización. Modelos y procesos históricos, Instituto de Estudios de la Administración Local, Madrid, 1985, pág. 395 y ss.

33 Cfr. L. JIMÉNEZ DE AsÚA: La Constitución de la democracia española y el problema regional, Ed. Losada, Buenos Aires, 1946.

34 Cfr. S. CARrillo: Memorias, Planeta, Barcelona, 1994, en particular, las páginas dedicadas a este periodo. Vid. asimismo El Partido Comunista de España ante las Constituyentes, Madrid, 1931. 
Una mención especial a los efectos del tema que nos ocupa merecen las fuerzas nacionalistas, que también van a hacer su aparición por primera vez en este periodo y que irán consolidándose progresivamente hasta erigirse en una de las principales fuerzas políticas, en sus respectivos territorios, en particular en Cataluña y en el País Vasco. En este caso sí va a haber un cuestionamiento claro del modelo de organización territorial del Estado por parte de las fuerzas nacionalistas; pero este cuestionamiento, como por otra parte resulta lógico desde una perspectiva nacionalista, no implica un proyecto alternativo de reorganización del Estado sino el establecimiento de un nuevo tipo de relaciones bilaterales con "Madrid". Esquema éste que es el que se empieza a esbozar durante la época de la II República y que, dicho sea de paso, es el que sigue manteniéndose en la actualidad, setenta años después. En cualquier caso, el planteamiento de las fuerzas nacionalistas en 193135, particularmente las catalanas y las vascas, es ajeno por completo a cualquier proyecto federal de reorganización territorial del Estado, orientándose en otra dirección distinta como era la de conseguir un status especial en el Estado, lo que como veremos más adelante tendrá su reflejo en el esquema de organización territorial que rigió efectivamente durante la II República.

En este contexto político, en el que las opciones federales apenas contaban entre las principales fuerzas políticas, difícilmente podían tener incidencia apreciable en el constituyente republicano; así se pone de manifiesto en el desarrollo del proceso constituyente, en el que, salvo algunas alusiones esporádicas al modelo federal, los principales ejes del debate en las Cortes Constituyentes en torno al modelo de organización territorial del Estado discurrieron por otros terrenos distintos al del federalismo ${ }^{36}$. Hay que reseñar, además, otro importante factor a tener en cuenta, que incidirá de forma determinante en la orientación del debate constituyente en general, y también en este tema en concreto, como es el del modelo constitucional de referencia para el constituyente de 1931. Ello nos obliga a hacer una breve alusión al constitucionalismo europeo de entreguerras, y de forma especial a la Constitución de Weimar, cuyo influjo sobre los artífices del texto

35 Sobre la posición de los nacionalismos ante la II República, vid. J. GoNzÁlez Beramend y R. MAIz (comps.), Los nacionalismos en la España de la II República, Siglo XXI, Madrid, 1991.

36 Vid. A. De Blas Guerrero: «El debate doctrinal sobre la autonomía en las Constituyentes de la II República", Revista de Historia Contemporánea. UPV7EHU, n. ${ }^{\circ} 6,1991$, pág. 119 y ss. 
constitucional de 1931 ha sido advertido de forma unánime por los comentaristas.

\section{El constitucionalismo de entreguerras y la racionalización de la organización territorial del Estado}

Como es sabido, uno de los rasgos distintivos del constitucionalismo de entreguerras es el intento de acometer la racionalización de la organización institucional del Estado, lo que hallará su reflejo en los propios textos constitucionales de la época. De acuerdo con esta nueva orientación van a ir apareciendo las primeras formulaciones constitucionales de racionalización parlamentaria, tema que ha sido objeto de especial atención entre los constitucionalistas desde los primeros momentos (y que ha continuado siéndolo después) ${ }^{37}$. Es en este nuevo contexto de racionalización constitucional de las instituciones políticas en el que, junto a las formulaciones ya señaladas de racionalización parlamentaria, aparecerán también una serie de propuestas encaminadas a la racionalización de la organización territorial del Estado. Aunque esta faceta del constitucionalismo de entreguerras no ha originado una literatura tan amplia como la dedicada al tema de la racionalización parlamentaria, y en particular a las relaciones ejecutivolegislativo, su interés resulta obvio tanto para la mejor comprensión global del constitucionalismo de entreguerras en su conjunto como, en particular, a los efectos del tema que nos ocupa ${ }^{38}$.

En el marco del constitucionalismo de entreguerras, la Constitución de Weimar ha sido considerada el texto más emblemático de este periodo; en primer lugar, por su propio contenido en sí mismo y por las innovaciones constitucionales que introduce; por otra parte, no puede

37 Sobre el constitucionalismo de esta época, es obligada la referencia a B. Mirkine Guetzevitch: Modernas tendencias del Derecho Constitucional, Edit. Reus, Madrid, 1934. Asimismo, vid. F. FernÁndez SEGADO: «El constitucionalismo de entreguerras (reflexiones al hilo de la obra de B. Mirkine-Guetzevitch)", Revista General de Legislación y Jurisprudencia, 1985, n. ${ }^{\circ} 4$, pág. 535 y ss.

38 Vid. Sobre este tema, en particular, J. CORCuera: «El constitucionalismo de entreguerras. La racionalización del poder y sus límites", en particular, el apartado "La revisión del federalismo", en Estudios de Derecho Público. Homenaje a J. J. Ruiz-Rico, vol. I, Tecnos, Madrid, 1997, pág. 73 y ss. Asimismo, el reciente trabajo del mismo autor (en prensa) "La Constitución española de 1931 en la historia constitucional comparada", en particular, el apartado "La racionalización del federalismo y el Estado integral», en Fundamentos, n. ${ }^{\circ} 2,2000$, Cuadernos monográfi$\cos$, Junta General del Principado de Asturias. 
pasar desapercibido el hecho de que donde rigió fuera precisamente en Alemania, país cuyo peso e influencia en Europa es de primer orden; además, y debido a todo ello, la Constitución de Weimar es, sin duda, uno de los textos que mayor proyección ha tenido en el constitucionalismo de la época; y en especial en el constitucionalismo republicano español de 193139. Si bien el influjo de la Constitución weimariana se extiende al conjunto de la Constitución republicana de 1931, en estas líneas vamos a limitarnos a hacer una breve referencia a los aspectos relacionados directamente con la organización territorial del Estado.

En este sentido, la Constitución de Weimar diseñaba un modelo de organización territorial del Reich que, en líneas generales y por similitud semántica con la expresión acuñada de "parlamentarismo racionalizado", podríamos caracterizar como federalismo racionalizado. Hay que precisar que se trata de una racionalización del federalismo en clave unitaria que configura este modelo con rasgos claramente diferenciados en relación con el modelo federal clásico, básicamente el americano USA, tanto por lo que se refiere a la organización de los poderes como al reparto competencial entre los Estados miembros y la Federación ${ }^{40}$. Es altamente ilustrativo al respecto que el texto de Weimar no utilice en ningún momento el término federal para definir al Estado (así como tampoco los de Federación o Estado miembro, a diferencia del texto constitucional americano). Ello no impide, sin embargo, que la Constitución alemana de Weimar prevea mecanismos de tipo federal, bien por lo que se refiere a la distribución de poderes (arts. 5, 6, 7 y ss.) o bien en lo relativo a la organización institucional, particularmente el Consejo del Reich (arts. 60 y ss.) como órgano de re-

39 La influencia de la Constitución de Weimar en el constituyente republicano de 1931 fue muy importante. Algunas de las figuras más destacadas de las Cortes constituyentes, empezando por el Presidente de la Comisión constitucional, L. JIMÉnEZ de AsÚA, y el Presidente del Gobierno, luego de la República, N. ALCALÁ ZAMORA, hacen constantes referencias a ella. Numerosos profesores españoles de la época (García Pelayo, Recasens Siches...) estudiaron en Alemania directamente la experiencia constitucional weimariana. F. AyALA traduce y prologa (1934) la obra de C. Sснміт: Teoría de la Constitución (Edición reciente en Alianza Universidad, Madrid, 1982); J. Rovira Armengol, por su parte, traduce los comentarios de O. Bühler sobre La Constitución alemana de 11 de Agosto de 1919, Labor, Madrid, 1931. Además de la influencia de la Constitución de Weimar, es preciso reseñar también la influencia de la Constitución austriaca de 1920; vid. Sobre este tema J. L. CascaJo: "Kelsen y la Constitución española de 1931 ", Revista de Estudios Políticos, n. ${ }^{\circ}$, págs. 243-255.

$40 \mathrm{Cfr}$. al respecto, C. Sснміт: Teoría de la Constitución, op. cit., pág. 345 y ss., así como los comentarios críticos de F. Ayala en la presentación de esta obra, págs. 13-18. 
presentación territorial. Pero, en líneas generales, se trata de una modalidad de federalismo pasado por un tamiz "racionalizador" de signo marcadamente unitarista.

Como en muchos otros aspectos, en materia de organización territorial del Estado el constituyente republicano de 1931 no puede sustraerse al influjo de la referencia weimariana. Si en 1873 el modelo de referencia para el constituyente republicano de entonces había sido el americano (ver supra), en 1931 este lugar le iba a ocupar el alemán de 1919, mucho más próximo en el tiempo y geográficamente; pero al igual también que entonces, no se trataba de hacer una copia mimética del modelo de referencia, ni tampoco una mera adaptación a la situación española, sino de elaborar un marco constitucional para la organización territorial del Estado acorde con la realidad propia ${ }^{41}$. Tal era el reto que se le planteaba al constituyente republicano de 1931, como va a haber ocasión de comprobar en el curso del breve pero intenso proceso constituyente que se desarrolla en los poco más de tres meses que preceden a la aprobación del texto constitucional republicano.

Un hecho en particular singularizaba la situación en España en relación con otros países en los que se había ensayado el modelo que hemos caracterizado como federalismo racionalizado: la existencia de movimientos nacionalistas, con notable implantación precisamente en las zonas más desarrolladas industrialmente en aquel momento - $\mathrm{Ca}$ taluña y País Vasco- cuyas revindicaciones difícilmente tenían encaje en ese modelo federal ( $\mathrm{ni}$ en ningún otro). Ello condicionaba por completo las respuestas del constituyente al problema de la organización territorial del Estado - como se puso de manifiesto con toda claridad desde el primer momento en Cataluña ${ }^{42}$ - obligándole a elaborar una alternativa constitucional que diese respuesta simultáneamente a las reivindicaciones nacionalistas catalanas y vascas, al tiempo que válida para el resto del territorio, donde la cuestión de la organización territorial del Estado se planteaba en términos sensiblemente diferentes.

41 Vid. L. VANDELLI: El ordenamiento español de las Comunidades autónomas, IEAL, Madrid, 1982; en particular, el apartado dedicado al "Debate doctrinal sobre la forma del Estado español en 1931 ", pág. 49 y ss.. Asimismo, vid. el trabajo de G. Ambrosini (citado por L. VandelLI, op. cit.) "Un tipo intermedio di Stato fra l'unitario e il federale caratterizzato dall'autonomie regionale", Rivista di Diritto Pubblico, 1993, pág. 93 y ss.

42 Cfr. J. A. González Casanova: «La Constitución de la República española y el Estatut de Catalunya de 1932", Sistema, n. ${ }^{\circ} 17-18$, pág. 99 y ss.. Sobre esta cuestión, vid. También el histórico discurso de M. Azaña en las Cortes (27 mayo 1932) Defensa de la autonomía de Cataluña, Ed. Undarius, Barcelona, 1977. 
Este era el marco político global en el que el constituyente republicano de 1931 tenía que abordar la cuestión pendiente, y reavivada en ese momento, de la organización territorial del Estado 43 . Y lo hizo aportando una solución original mediante el diseño de un modelo de Estado que difiere del federal clásico ( $y$ del federalismo racionalizado, aunque con algunos elementos comunes en este último caso) así como del modelo tradicional unitario centralizado, que inicialmente va a recibir la denominación de Estado integral y que posteriormente conoceremos como Estado autonómico.

\section{El Estado integral}

"La República constituye un Estado integral, compatible con la autonomía de los Municipios y las Regiones». Estos son los términos en los que se expresa la Constitución de 1931 (art. 1, par. $3^{\circ}{ }^{\circ}$ al referirse al Estado en relación con las entidades territoriales municipales y regionales. Asimismo, el Tít. l, dedicado a la "Organización nacional», establece que «El Estado español... estará integrado por Municipios mancomunados en provincias $y$ por las Regiones que se constituyan en régimen de autonomía" (art. 8). En ambas disposiciones se basa la caracterización del Estado como integral, de forma directa y expresa en el art. $1 .^{\circ}-$ Estado integra $-\mathrm{y}$ aludiendo a los entes territoriales que le integran en el art. $8 .^{\circ}-$ Municipios mancomunados en provincias y $R e$ giones que se constituyen en régimen de autonomía-. A partir de estos iniciales enunciados constitucionales es preciso delimitar, a continuación, su significado y su alcance para así poder aproximarnos a la novedosa noción de Estado integral, según los términos acuñados por el constituyente republicano 44 .

43 Sobre el marco político global en ese momento, vid. M. TUÑón DE LARA: "La cuyuntura histórica española de 1930-31", Revista de Estudios Políticos, n. ${ }^{\circ} 31$ 32, pág. 39 y ss. Asimismo, vid. J. Tusell, O. Ruiz Manjón y G. Garcia Queipo de llano: "Las Constituyentes de 1931: unas elecciones de transición", Revista de Derecho Político, n. ${ }^{\circ} 12$, pág. 189 y ss.

44 La noción de Estado integral fue objeto de comentarios muy críticos por los constitucionalistas de la época. Vid., entre otros, N. Pérez Serrano, que se refiere a ella como una fórmula "absolutamente vacía de sentido" (La Constitución española (9 Diciembre 1931). Antecedentes, texto, comentarios, Ed. Revista de Derecho Privado, Madrid, 1932, pág. 62). A. Royo Villanova, por su parte, habla de "frase esotérica" y de "camelo" (La Constitución española de 9 de Diciembre de 1931, con glosas jurídicas y apostillas políticas, Imp. Castellana, Valladolid, 1934, pág. 24). 
Procediendo, a efectos didácticos, por exclusión, puede afirmarse que el modelo de organización territorial que contempla la Constitución republicana de 1931 no es asimilable al modelo unitario centralizado ya que, además de la referencia genérica a la compatibilidad del Estado (integral) con la autonomía municipal y regional, hay una previsión constitucional expresa para las Regiones de un régimen de autonomía específico para ellas. A reserva de la concreción de los regímenes autonómicos regionales por medio de los respectivos Estatutos de autonomía, lo cierto es que las referidas disposiciones constitucionales -especialmente la segunda de ellas (art. $8 .^{\circ}$ ) insertada en el Tít. I relativo a la "Organización nacional» - hacen referencia a la autonomía como un elemento estructural del Estado. Nos hallamos, por tanto, ante un modelo de Estado que difiere del modelo unitario centralizado.

Asimismo, y en relación con el otro modelo clásico de organización territorial del Estado -el federal一, también resulta evidente que no cabe su asimilación con él. En primer lugar porque el constituyente republicano rechaza expresamente la opción federal cuando ésta se planteó en el debate constituyente, lo que ponía claramente de manifiesto que optaba, de forma consciente, por otra opción distinta de la federal. Pero también por el diseño de la organización territorial del Estado (integral), cuyas diferencias con el esquema institucional propio del Estado federal son notorias (por ej. la ausencia de una Cámara de representación territorial; o el papel constitucional reservado a los entes territoriales, entre otras). Así pues, y aunque sólo sea por exclusión, podemos concluir provisionalmente en una primera aproximación que el Estado integral al que alude la Constitución republicana de 1931 (y el modelo de organización territorial que comporta) hace referencia a un ente estatal de naturaleza distinta aun por definir ${ }^{45}$.

A falta de una teorización previa sobre el tema -como la que podía existir, por ejemplo, sobre el Estado federal- es obligado remitirse al debate en la Cortes constituyentes en torno a esta cuestión; y más concretamente a la postura mantenida al respecto por los principales protagonistas en la discusión del proyecto constitucional, empezando por el propio Presidente de la comisión que elaboró el proyecto, L. Jiménez de Asúa, quien en el discurso de presentación de éste ante el

45 En este sentido, vid. J. TOMÁs VILLARRoya, para quien se trata de una noción de contenido indeterminado (Breve historia del constitucionalismo español, op. cit., pág. 126); asimismo, L. SÁNCHEZ AGESTA, quien lo califica como un término anfibológico (Historia del constitucionalismo español, op. cit., pág. 489). 
pleno se expresaba en los siguientes términos: «Deliberadamente no hemos querido declarar en nuestra Carta Constitucional que España es una República federal; no lo hemos querido declarar porque hoy, tanto el unitarismo como el federalismo están en franca crisis teórica y práctica [...] La autonomía va haciendo que, en vez de tratarse de una Constitución federal, se trate de algo de lo que he de hablar más tarde: de un Estado integral. Está pues en franca crisis todo lo referente a esta antítesis de Estado federal y Estado unitario. El Estado unitario estaba ya en franco crack desde el comienzo de la presente centuria... Pero al mismo tiempo tampoco puede el sistema federal ofrecernos bases teoréticas y prácticas; el sistema sinalagmático de pacto que ilustró $\mathrm{Pi}$ y Margall hoy no se recibe por la teoría ni por la práctica... Esto es lo que ha querido hacer la Comisión: un Estado integral... Eso es lo que en la Constitución ofrecemos y queremos hacer, y así vemos claramente atacado el unitarismo en los arts. 15 y 19, no admisión del federalismo en los arts. 14 y 17 y, en cambio, proclamado el integralismo absoluto en los arts. 16,18 y $20 » 46$.

La posición expresada por el Presidente de la Comisión constitucional es compartida también por otras destacadas figuras de las Cortes constituyentes; entre otros, cabe mencionar a Sánchez Albornoz, quien en nombre del minoritario pero influyente grupo de Acción Republicana aplaude "la tendencia autonomista de la Constitución", se pronuncia a favor del reconocimiento de "las autonomías que la diferenciación regional exige" y se refiere al Estado como «Estado integral autonómicon 47 .

Dos conclusiones cabe extraer de estas manifestaciones en el debate constituyente: en primer lugar, que el constituyente republicano opta deliberada y conscientemente por un modelo de Estado distinto del federal y del unitario, como se pone claramente de manifiesto en la intervención de Jiménez de Asúa. $Y$, seguidamente, que la noción de Estado integral está vinculada directamente a la de autonomía, hasta el punto que se llega a utilizar expresivamente los términos de "Estado integral autonómico" (Sánchez Albornoz). Podría añadirse también, de acuerdo con los términos en los que se expresa el Presi-

46 Estas frases del discurso de L. JIMÉNEZ DE AsúA en la presentación en las Cortes del proyecto constitucional (cfr. D. SeVILla Andrés: Constituciones..., op. cit., págs. 206-207) son sumamente ilustrativas de la posición del constituyente republicano ante el modelo de Estado. to 1931$)$.

47 Intervención de SánChez Albornoz en las Cortes Constituyentes (27 agos- 
dente de la Comisión constitucional, que se trata de un Estado «mixto" en tanto se prevé la existencia de elementos de tipo federal en algunos casos - se llega incluso a afirmar (Jiménez de Asúa) que «en muchas partes nuestra Constitución es más federal, valga la palabra, que la de la propia Austria»- al tiempo que en otras ocasiones se excluye expresamente el federalismo, así como el unitarismo (ver supra) y, por último, se admite un régimen de autonomías diversificado: "en este sistema integral, que cada una de las regiones reciba la autonomía que merece por su grado de cultura y progreso; unas querrán quedar unidas, otras tendrán su autodeterminación en mayor o menor gradon 48 .

En definitiva, el Estado integral ha de ser entendido como un nuevo tipo de Estado, distinto del unitario $y$ del federal, basado en la autonomía de los entes territoriales que le integran en los términos que precisa la propia Constitución (Tít. I. "Organización nacional», arts. 822) y los Estatutos de Autonomía que se aprueben. En este modelo de Estado coexisten, por lo que se refiere a la organización territorial del Estado, elementos federales junto a otros propios del Estado unitario, admitiéndose, por último, una diversificación de los regímenes autonómicos en función de la voluntad expresada por las distintas regiones que aspiren a dotarse de un régimen de autonomía.

Es preciso puntualizar, para finalizar, que los términos Estado integral no figuraban en el texto del proyecto constitucional (ni tampoco en el Anteproyecto elaborado por la Comisión Jurídica Asesora) ${ }^{49}$ y fueron incorporados a la redacción definitiva en el curso del debate constituyente, al discutirse sobre la composición territorial del Estado. Una vez incorporados al texto constitucional, esta expresión aparece vinculada a los entes territoriales que integran el Estado (arts. 1 y 8 ). Se trata, por tanto, de una noción relacionada directamente con la organización territorial del Estado tanto por la forma en que es incorporada al texto constitucional como por su ubicación en él; en este sentido, son discutibles las tesis que extienden el alcance de la noción de Estado integral a otros terrenos ajenos al de la estructura territorial, tales como

48 L. JIMÉNEZ DE AsÚA, en el referido discurso de presentación del proyecto constitucional (cfr. D. Sevilla Andrés: Constituciones..., op. cit., pág. 207).

49 Este proyecto, incluidos los votos particulares que se formularon, puede hallarse en su integridad en D. SevLLLA ANDRÉs: Constituciones..., op. cit., págs. 139198. Aunque el texto constitucional finalmente aprobado difiere sensiblemente de este Anteproyecto, no deja de tener interés ya que permite comprender la evolución que siguió el proceso constituyente republicano. 
la integración de clases o la integración social y política en general50, ya que la función integradora, en general, del Estado constitucional es inherente a su propia naturaleza, independientemente de la forma de gobierno o de organización territorial que adopte, $y$ no un rasgo distintivo de un tipo de Estado en particular.

\section{El marco constitucional de la autonomía regional}

A diferencia del proyecto constitucional republicano de 1873 , la Constitución de 1931 no determina el nuevo mapa territoria|51, limitándose a prever la existencia de regímenes de autonomía regional que, juntamente con "los municipios mancomunados en provincias", integran el Estado español (art. 8). A continuación se fijan los criterios y los cauces para acceder al régimen de autonomía y, según los términos empleados en el texto constitucional, "para formar un núcleo políticoadministrativo, dentro del Estado español" (art. 11); así como también para la elaboraión y aprobación del Estatuto, que userá la ley básica de la organización politico-administrativa de la región autonómica" (art. 11). Hay que precisar que la Constitución no predetermina cuantas ni cuales van a ser las regiones autónomas ni tampoco el contenido ni las formas del régimen de autonomía sino que se ciñe a establecer el marco constitucional de la autonomía regional sobre la base del principio de voluntariedad por lo que se refiere al acceso al régimen autonómico y al perfil de éste en cada caso.

\subsection{El acceso a la autonomía. Los Estatutos de autonomía}

De acuerdo con el marco constitucional que establece el Tít. I, dedicado a la "Organización nacional", y con el principio de voluntariedad precitado, para acceder al régimen autonómico se requiere que así lo acuerden «una o varias provincias limítrofes, con características históricas, culturales y económicas comunes» (art. 11). Esta voluntad au-

50 Vid. En este sentido, F. TOMÁs Y VALIENTE: “El Estado integral. Nacimiento Y virtualidad de una fórmula poco estudiada", Obras completas III, Centro de Estudios Políticos y Constitucionales, Madrid, 1997, págs. 2041-2054.

51 Al igual que la Constitución de Weimar, que tampoco fija el mapa territorial alemán; $y$ a diferencia de las constituciones federales, que suelen ocuparse expresamente de esta cuestión. Así, por ej., la Constitución suiza (art. 1), la Constitución austriaca (art. 2), la Ley Fundamental de Bonn (preámbulo), y la actual Constitución belga (arts. 2, 3, 4 y 5). 
tonómica, que tendrá su plasmación en el texto estatutario, ha de ser acreditada a través de los municipios, estableciéndose para ello una serie de condiciones que, en los términos en que están planteadas, parecen estar destinadas a comprobar que la voluntad autonómica existe realmente 52 . Así, se exige que la propuesta estatutaria esté respaldada por los Ayuntamientos de los municipios que representen "cuando menos... las dos terceras partes del censo electoral de la Región" (art. 12). Además, una vez elaborado el texto del Estatuto, éste deberá ser sometido a la consulta de la población para su aceptación por una mayoría de upor lo menos las dos terceras partes de los electores inscritos en el censo de la región" (art. 12). Se trata, como puede observarse, de unas mayorías muy elevadas, quizá excesivas, que en caso de alcanzarse no dejan lugar a dudas sobre la voluntad autonómica de la población evitándose así el riesgo de crear autonomías artificiales 53 .

Hay que puntualizar que el cómputo de las mayorías referidas se hace a escala regional, no provincial, lo que puede inducir a que una provincia, que en principio son los entes territoriales que, de acuerdo con las previsiones constitucionales, pueden acordar "organizarse en región autónoma" (art. 11), podría verse incorporada a una región autónoma contra su voluntad. Ello resulta, además, contradictorio con la posibilidad, prevista también constitucionalmente, de que una provincia se desvincule de la región autónoma en que está incluida para pasar a tener una vinculación directa con el Poder central (art. 22). Parecería más razonable haber previsto la no incorporación a una región autónoma de aquellas provincias cuya población expresara mayoritariamente su voluntad contraria a formar parte de ella.

Finalmente, la aprobación definitiva del Estatuto exige la previa aprobación por las Cortes Generales, que deberán hacerlo «siempre que se ajuste al presente Título [Tít. I] y no contenga, en caso alguno, preceptos contrarios a la Constitución" (art. 12). A juzgar por los términos en que está redactada esta disposición constitucional, estimamos que la función que se le asigna a las Cortes en el proceso de aprobación de la norma estatutaria debe ceñirse a verificar su conformidad con la Constitución, debiendo proceder a su aprobación en este supuesto; no obstante, el inciso final del párrafo que comentamos - "sin perjuicio de la facultad que a las Cortes reconocen los arts. 15 y $16 \%$,

52 Vid. M. B. García Álvarez: "La voluntad regional como origen de la autonomía política en la II República", Sistema n. ${ }^{\circ} 14$, págs. 73-93.

53 Sobre esta cuestión, vid. A. HeRnández LAFUENTE: "Los referemdums de autonomía en la II República", Revista de Estudios Políticos, n. ${ }^{\circ} 5$, pág. 97 y ss. 
que hacen referencia al reparto competencial entre el Estado y las regiones autónomas - ha dado pie a una interpretación distinta en virtud de la cual las Cortes estarán facultadas para hacer una valoración politica sobre la oportunidad y la conveniencia de la aprobación del Estatuto $^{54}$. En cualquier caso, y no compartiendo por nuestra parte esta última posición, estimamos que el mencionado inciso final (muy defectuoso técnicamente ya que se refiere innecesariamente a dos disposiciones -arts. 15 y 16 - que quedan incluidas en la referencia previa en este mismo artículo a la Constitución y al presente Título) no puede desvirtuar el significado del enunciado inicial del párrafo en el sentido ya indicado de verificación de la constitucionalidad de los Estatutos de autonomía.

Sobre la naturaleza jurídica del Estatuto, la Constitución se limita a decir que, una vez aprobado éste por el procedimiento reseñado, "será la ley básica de la organización político-administrativa de la región autónoma, y el Estado español la reconocerá y amparará como parte integrante de su ordenamiento jurídico" (art. 11). De acuerdo con este enunciado, la primera caracterización que cabe hacer de las normas estatutarias es que a ellas está reservada la articulación institucional de la autonomía regional, lo que las singulariza en relación con el resto de las normas del ordenamiento jurídico, tanto en el ámbito estatal como en el específicamente regional. Por lo que respecta a éste último en particular, los Estatutos tendrán la consideración de ley superior en su propio ámbito, que establece el marco jurídico en el que han de desarrollar su actividad los órganos autonómicos regionales.

En relación con el ordenamiento jurídico estatal, del que los Estatutos son parte integrante, se plantea el problema de determinar el lugar que ocupan en él. En este sentido, podemos avanzar, de acuerdo con la doctrina al respecto, que no se trata de "una ley ordinaria, sin más»55, tanto por la reserva expresa que la propia Constitución hace sobre su contenido material — «ley básica de la organización políticoadministrativa de la región autónoma" (art. 11) - como por la forma de su elaboración y aprobación (ver supra) que, a diferencia de cualquier otra ley requiere la participación directa de la población en el ámbito territorial de la región autónoma. Asimismo, la reforma del Estatuto si-

54 Posición mantenida, en su momento, por S.Royo: "El Estado integral», Revista de Derecho Público, n. ${ }^{\circ} 45$, (1935), pág. 265; y, asimismo, por N. Pérez SERRANO: La Constitución española..., op. cit., pág. 94; y en la actualidad por F. FernáNdez Segado: Las Constituciones históricas..., op. cit., pág. 619.

55 Vid. F. Fernández Segado, op. cit., pág. 621. 
gue un procedimiento distinto del de las leyes ordinarias; aunque la Constitución no precisa esta cuestión, los dos Estatutos aprobados - el catalán en 1932 y el vasco en 1936- preveían un procedimiento en el que, junto a la participación de los órganos autonómicos y del electorado del territorio autónomo, se exigía una mayoría cualificada de dos tercios en las Cortes Generales para aprobar la reforma estatutaria (la misma exigida para reformar la propia Constitución durante los cuatro primeros años a partir de su aprobación; después sólo se exigía la mayoría absoluta). Ello dotaba a las normas estatutarias de un rasgo común con las normas constitucionales, como es el de la rigidez, si bien no cabe deducir de esta característica común su equiparación en cuanto al rango constitucional de ambas.

\subsection{El ámbito competencial del Estado y de la autonomía regional}

En la delimitación del ámbito competencial propio de la autonomía regional, por una parte, y del Estado, por otra, la experiencia constitucional comparada de la época - la Constitución alemana de Weimar y, de forma especial, la Constitución austriaca de 1920- sirvió de modelo de referencia al constituyente republicano de 1931. Son ilustrativas al respecto las palabras de Ossorio y Gallardo en el preámbulo del Anteproyecto constitucional, al afirmar que "nos hemos guiado por lo que establecen las Constituciones federales de Europan56. Hay que puntualizar, no obstante, que si bien es cierto que éstas sirvieron de referente en la distribución de competencias entre el Estado y las Regiones autónomas, el modelo definitivamente adoptado por el constituyente republicano presenta rasgos distintivos en relación con aquéllas.

En síntesis, el esquema de reparto competencial se basaba en una doble lista, la primera de las cuales reservaba a "la exclusiva competencia del Estado español la legislación y la ejecución directa» en una serie de materias que se especificaban a continuación (art. 14); la segunda lista hacía referencia a las materias en las que "corresponde al Estado la legislación y podrá corresponder a las regiones autónomas la ejecución» (art. 15)57. Hay que llamar la atención, en esta segunda lis-

56 Cfr. D. Sevilla Andrés: Constituciones..., op. cit., pág. 140. Asimismo, en la presentación del proyecto constitucional por L. JIMÉNEZ DE AsúA (cfr. op. cit., págs. 203-213), las alusiones a las Constituciones alemana y austriaca son reiteradas.

57 Algunos autores hablan de un esquema "tripartito" de reparto competencial, siendo aquellas materias no comprendidas en ninguna de las dos listas an- 
ta, sobre las prevenciones con que se contempla la atribución de las competencias de ejecución a las regiones autónomas, que de acuerdo con los términos en que está redactada esta disposición sólo podrán ser asumidas por éstas "en la medida de su capacidad política, a juicio de las Cortes" (art. 15). Sorprende esta cláusula, sumamente restrictiva para la autonomía regional (incluso hasta humillante para las Regiones autónomas), al otorgar a las Cortes la facultad para evaluar en todo momento algo tan indefinido como la "capacidad política" de las regiones; máxime tratándose de competencias de ejecución, en las que en caso de incumplimiento o de cumplimiento defectuoso de las mismas por los órganos regionales pueden utilizarse otros instrumentos, previstos además constitucionalmente de forma expresa, tales como el de la inspección por parte de los órganos estatales competentes.

Determinado el ámbito competencial del Estado mediante la doble lista reseñada (arts. 14 y 15), el ámbito competencial de la autonomia regional estará integrado por todas aquellas materias no incluidas en esas listas, sobre las que los órganos autonómicos podrán tener competencias en "la legislación exclusiva y la ejecución directa, conforme a lo que dispongan los respectivos Estatutos aprobados por las Cortes" (art. 16). Esta atribución genérica de competencias - no hay lista que predetermine el ámbito de la autonomía regional en la Constitución; esa lista estará en los respectivos Estatutos de autonomía- ha de ser completada con la cláusula de los poderes residuales en favor del Estado: "todas las materias que no estén explícitamente reconocidas en su Estatuto a la Región autónoma, se reputarán propias de la competencia del Estado" (art. 18). Por último, esta misma disposición constitucional prevé la posibilidad de transferir, a su vez, estas competencias, mediante ley, en favor de las Regiones.

El modelo de distribución competencial58 se cerraba con una serie de previsiones constitucionales relativas, la primera de ellas, a la facultad del Estado para fijar, mediante ley, "las bases a las que habrán de ajustarse las disposiciones legislativas de las regiones autónomas, cuando así lo exigiere la armonía entre los intereses locales y el interés general de la República» (art. 19). Interesa reseñar que estas leyes deberán ser aprobadas por una mayoría de dos tercios del total de los diputados, lo que de hecho hacía muy difícil la aprobación de cualquier

teriores (arts. 14 y 15) las que integrarian el tercer bloque competencial, que podían asumir las regiones autónomas mediante sus respectivos Estatutos (art. 16).

58 Sobre el debate en las Cortes constituyentes en torno a esta cuestión, vid. F. Fernández Segado: Las Constituciones históricas..., op. cit., pág. 625 y ss. 
norma legislativa en este sentido. Por otra parte, y en el marco del principio general según el cual corresponde a las autoridades autonómicas la ejecución de las leyes de la República (salvo cuando expresamente se disponga lo contrario) se reservaba al Gobierno de la República la facultad de "dictar Reglamentos para la ejecución de sus leyes, aun en los casos en que esta ejecución corresponda a las autoridades regionales" (art. 20). Se trata de una disposición muy discutible desde el punto de vista autonómico ya que comporta, en palabras de Segismundo Royo, una "fiscalización administrativa del Estado sobre las regiones", que reduce al mínimo el ámbito de la autonomía regional y que puede llegar incluso a ser contradictoria con otras disposiciones constitucionales (art. 15) ${ }^{59}$. Finalmente, el art. 21 constitucionaliza expresamente la cláusula de supremacía, en virtud de la cual «El derecho del Estado español prevalece sobre el de las regiones autónomas en todo lo que no esté atribuido a la exclusiva competencia de éstas en sus respectivos Estatutos".

\subsection{El principio de igualdad en las relaciones autonómicas}

Aunque el principio de igualdad y de no discriminación es un principio inherente al propio Estado constitucional, sin el que éste no es concebible, independientemente de que haya o no una alusión explícita a él, suele ser objeto de constitucionalización expresa en los textos constitucionales actuales 60 , tanto con carácter general como en determinados ámbitos específicos en los que puede haber riesgo de vulneración. En este sentido, la Constitución republicana de 1931, además de la afirmación genérica del principio de igualdad ante la ley (art. 2) y de exclusión de las discriminaciones (art. 25) contiene una referencia expresa al respecto en el ámbito específico de las relaciones autonómicas en los siguientes términos: "En las regiones autónomas no se podrá regular ninguna materia con diferencia de trato entre los naturales del país y los demás españoles" (art. 17).

Es obvio que lo que la mencionada disposición constitucional no admite es la diferencia de trato, ya que ello vulneraría el principio de igualdad; pero no una regulación diversa y diferenciada de las materias que integran el ámbito competencial de las Regiones autónomas de

59 S. RoYo: "El Estado integral», op. cit., pág. 268.

60 Arts. 3 y 33 de la Constitución alemana; art. 7 de la Constitución austriaca y art. 6 del Tratado sobre el restablecimiento de Austria (1955) arts. 10 y 11 de la Constitución belga. 
acuerdo con la Constitución y los respectivos Estatutos. Esta diversidad es precisamente la consecuencia lógica y la expresión natural del principio de autonomia, que no tiene porqué entrar en contradicción con el de igualdad. En cualquier caso, y aunque en el plano teórico no hay dificultades para admitir la compatibilidad entre ambos principios, sí es cierto que en la práctica ésta es una cuestión en la que suelen plantearse de hecho numerosos y complejos problemas, ya que no es fácil dilucidar, a veces, si una determinada regulación de una materia por los órganos autonómicos puede comportar desigualdad de trato o no61. En este supuesto, el litigio deberá ser zanjado por el Tribunal de Garantías Constitucionales.

\section{La organización institucional del Estado}

A diferencia del proyecto constitucional republicano de 1873, que comportaba una reorganización de las instituciones del Estado (federal) acorde con la nueva estructura territorial, en particular en lo concerniente a la composición del Senado como Cámara de representación territorial (ver supra), la Constitución de 1931 no introduce modificaciones en el esquema de organización institucional del Estado en relación con los entes territoriales que le integran. Ello era una consecuencia directa del rechazo expreso de la opción federal por parte del constituyente de 1931, que va a mantener en el Estado integral el esquema de organización institucional propio del modelo unitario; en particular por lo que se refiere a la instancia parlamentaria, en la que no se contemplará la existencia de ninguna Cámara de representación territorial autonómica.

Si bien el tema del bicameralismo se planteó en el debate constituyente62, la opción monocameral fue clara desde el primer momento como lo pone de manifiesto el hecho de que esta opción era por la que se pronunciaba ya el proyecto de la Comisión constitucional. Hay que decir, además, que en el Anteproyecto de la Comisión Jurídica Asesora que precedió a aquél, donde sí se planteaba un modelo bicameral, éste, sin embargo, no respondía al esquema federal ni tampoco

61 Sobre la problemática que suscita este tema, desde una perspectiva comparada (Suiza, Alemania, USA, además de España), vid. J. Pemán Gavín: Igualdad de los ciudadanos y autonomías territoriales, Cívitas, Madrid, 1982.

62 Principalmente por parte de los grupos radical (R. Samper), liberal-republicano (N. Alcalá Zamora) e independiente (Melquiades Alvarez). Cfr. F. FernánDEZ SegAdo: Las Constituciones históricas..., op. cit., págs. 633 y ss. 
al de otras formas de representación territorial; tan sólo tangencialmente se aludía a esta cuestión; en concreto, reservando 115 de los senadores (50 sobre 250 ) a los entes territoriales, incluyendo en ellos tanto a las regiones como a las provincias y a los municipios (art. $37 \mathrm{del}$ Anteproyecto). Pero, en ningún caso puede decirse que se planteasen formas específicas de representación territorial, y las enmiendas que se formularon en este sentido en el curso del debate constituyente fueron todas ellas rechazadas 63 .

En definitiva, el nuevo diseño autonómico del Estado integral apenas tuvo reflejo en la composición y estructura de las Cortes. Si esto era lo que ocurría en el máximo órgano representativo, que es el más idóneo para reflejar la pluralidad territorial, resulta obvio que ésta menos aún iba a verse reflejada en otros órganos como el ejecutivo o el judicial, que tampoco se vieron afectados por la regionalización autonómica. Va a ser, sin embargo, en un nuevo órgano, que la Constitución republicana de 1931 instituye por primera vez64, como es el Tribunal de Garantías Constitucionales, donde sí van a poder apreciarse algunos elementos relacionados con la nueva estructura autonómica del Estado.

En este sentido, las disposiciones dedicadas al Tribunal de Garantías Constitucionales (Tít. IX, arts. 121-124) contienen referencias expresas a las Regiones autónomas, a las que se reconoce como partes en los conflictos de competencia legislativa o en cualesquiera otros que pudieran surgir entre ellas o con el Estado (art. 121-c), así como la legitimación para "acudir al Tribunal de Garantías Constitucionales» (art. 123.3)65. Igualmente, al regular la composición de este órgano se prevé que en él esté presente "un representante por cada una de las Regiones españolas en la forma que determine la ley" (art. 122). Interesa reseñar que es en la regulación de este nuevo órgano donde aparece la única referencia constitucional a las Regiones en relación con la organización territorial del Estado.

63 Tres años después de aprobada la Constitución, N. AlCALÁ Zamora volverá a ocuparse de este tema, reiterando su posición crítica: Los defectos de la Constitución de 1931 y tres años de experiencia constitucional, op. cit., pág. 289 y ss.

64 Existía el precedente, ya señalado (ver supra) del Tribunal Supremo Federal en el proyecto constitucional de la I República (1873), aunque este órgano no llegó siquiera a constituirse. Sobre este tema, vid. S. A. Roura: La defensa de la Constitución en la historia constitucional española, Centro de Estudios Políticos y Constitucionales, Madrid, 1998, pág. 226 y ss.

65 Para un estudio más amplio sobre este órgano, vid. la reciente obra de S. A. Roura: La defensa de la Constitución..., op. cit., pág. 297 y ss. 
Por otra parte, la ley orgánica especial que, según las previsiones constitucionales (art. 124), debía ocuparse de regular este órgano, contiene la única referencia al mapa territorial del Estado autonómico que, como ya hemos señalado, carece de reflejo constitucional (a diferencia también del proyecto constitucional de la I República). En ella se enumeran expresamente, por orden alfabético, cada una de las regiones no autónomas - todas menos Cataluña, en ese momento (1933)66-. Se regulaba también en esta ley la forma de elección de los representantes de cada una de las regiones en el Tribunal de Garantías Constitucionales, que difería según se tratase de Regiones autónomas -el Parlamento autónomo- o no autónomas - un colectivo electoral compuesto por los concejales de los Ayuntamientos de la Región-. Curiosamente, es éste el único órgano constitucional en el que las Regiones, tanto las autónomas como las no autónomas, tienen representación como tales.

\section{El fin de la experiencia autonómica republicana y la pervivencia del modelo autonómico}

La breve y limitada experiencia autonómica de la II República hace difícil la evaluación sobre el funcionamiento efectivo del sistema autonómico. Como es sabido, tan sólo en Cataluña rigió efectivamente un régimen de autonomía estatutaria; y ello durante un breve periodo de tiempo, con interrupciones además, que no llegó a los cuatro años. En el País Vasco, el Estatuto fue aprobado una vez iniciada la guerra civil y no tuvo vigencia más que en una parte del territorio - Vizcaya, y no en su totalidad-durante unos meses y en plena guerra. En Galicia, el Estatuto, aunque plebiscitado, no llegó siquiera a aprobarse. En estas condiciones, que son las que realmente se dieron, la experiencia autonómica republicana no permite extraer conclusiones fundadas, más allá de la constatación del intento de ensayar una nueva y original forma política —el Estado integral auto-

66 El art. 11 de la mencionada ley (30 de junio de 1933) establece el mapa regional de las regiones no autónomas, con la excepción de Cataluña que era la única que habia accedido en esa fecha a un régimen de autonomía. Eran las siguientes: Andalucia, Aragón, Asturias, Baleares, Canarias, Castilla la Nueva, Castilla la Vieja, Extremadura, Galicia, León, Murcia, Navarra, Vascongadas y Valencia, precisando también las provincias que integraban cada Región. El texto íntegro de esta ley puede hallarse en D. SeVILLA Andrés: Constituciones..., op. cit., pág. 281 y ss. Es interesante la comparación entre este mapa territorial, el anterior de la I República (ver supra) y el actual mapa autonómico. 
nómico- que diese respuesta a la cuestión pendiente de la organización territorial del Estado.

Es aventurado, además de completamente inútil, hacer cualquier predicción retrospectiva sobre la evolución que hubiera podido seguir el sistema autonómico diseñado por la Constitución republicana de 1931 y los Estatutos de autonomía que se aprobaron (y los que, sin duda, se hubieran podido aprobar después/67 en el supuesto de que la II República hubiese tenido continuidad histórica. Como es sabido, el desenlace de la guerra civil se saldó con el triunfo militar de los sublevados contra la República... y contra el régimen de autonomías que ésta había hecho posible y que era una de las cuestiones principales que concitaban la animadversión más radical en el bando antirepublicano por entender que atentaban contra la unidad nacional. El régimen instaurado tras la guerra civil supone la supresión de todo vestigio autonómico y la implantación de un modelo de organización territorial basado en el centralismo en su expresión más exacerbada.

Pero el trágico y cruento final de la experiencia autonómica republicana en España en 1936-39 no impidió, sin embargo, su pervivencia, sirviendo como modelo de referencia en otros países que, tras la II Guerra Mundial, van a abordar la reorganización territorial del Estado inspirándose en criterios similares a los configuraron el régimen autonómico de la II República española. Tal es el caso, particularmente, de Italia que, con la Constitución de 1947, va a adoptar un modelo de organización territorial del Estado basado en las autonomías regionales cuyo parentesco con el republicano de 1931 es evidente68. Asimismo, otros países como Bélgica, más tarde, cuando acometa, a partir de los

67 Además de los Estatutos de Cataluña (1932) y del País Vasco (1936) y del plebiscitado en Galicia (1936), el movimiento autonomista se extendió a otras regiones, que durante estos años empezaron a elaborar sus respectivas propuestas estatutarias. Los textos de estos proyectos estatutarios pueden hallarse en J. A. Santamaria, E. Orduña y R. Martin Artajo: Documentos para la historia del regionalismo en España, Instituto de Estudios de la Administración Local (IEAL), Madrid, 1977.

68 La influencia de la Constitución republicana española de 1931 sobre el constituyente italiano de 1946-47 ha sido subrayada por los comentaristas de ambos textos constitucionales. Vid. en este sentido L. VANDELLI: El ordenamiento regional de las Comunidades Autónomas, IEAL, Madrid, 1982, pág. 43 y ss. Una referencia especial merece G. AmBrosini, destacado miembro de la Asamblea constituyente italiana (1946-47), autor de un conocido comentario a la Constitución de 1931: «Un tipo intermedio di Stato fra l'unitario e it federale caratterizzato dall'autonomia regionale", Rivista di Diritto Pubblico, 1933, pág. 39 y ss. (cit. por L. VANDELLI, op. cit., pág. 52). 
años 60 la reorganización territorial del Estado, se van a inspirar también en el modelo autonómico como lo muestra el desarrollo del proceso de descentralización política seguido, que tendrá su plasmación en las reformas constitucionales de 1970 y 1980 . Y, aunque salvando las distancias y teniendo en cuenta la disparidad de los modelos jurídico y político anglosajón y español (y continental, en general), Gran Bretaña con los proyectos de devolution para Escocia y Gales desde finales de la década de los setenta. Por último, Francia, paradigma clásico del modelo unitario centralizado, iniciará también, a partir de 1982, un tímido proceso de regionalización 69 .

Finalmente, no podemos concluir sin reseñar la incidencia que la experiencia autonómica de la II República ha tenido en la configuración constitucional de nuestro actual Estado autonómico. Si bien este es un tema que, por sí solo, merece un estudio monográfico que no es posible desarrollar aquí70, baste decir, a modo de conclusión final, que independientemente de las similitudes y elementos comunes que pueden detectarse en las Constituciones de 1931 y 1978 por lo que se refiere a la organización territorial del Estado, como lo pone de manifiesto el análisis comparativo de ambos textos constitucionales, el actual régimen autonómico no hubiera sido posible sin el precedente republicano de 1931. Es ésta, sin duda, la más clara muestra de supervivencia histórica del espíritu constitucional republicano de 1931, del que el actual Estado autonómico es, en gran medida, deudor.

69 Sobre las experiencias europeas de regionalización autonómica en este periodo, vid. T. R. FERnÁNDEZ: "Aspectos institucionales del regionalismo. Planteamiento general y opciones básicas", Las autonomias regionales. Aspectos jurídicos y políticos, Presidencia del Gobierno, Madrid, 1977, págs. 315-336. Para un estudio más amplio sobre este tema desde una perspectiva comparada, vid.: "La regionalizzazione in Europa Occidentale" (Gran Bretaña, Francia, Bélgica, Austria, Alemania, además de España), en AA.VV.: La regionalizzazione, vol. II, ISAP, Giuffré, Milano, 1983; asimismo, AA.VV. (YVEs MeNY, dir.): Dix ans de regionalisation en Europe (1970-1980) (Bélgica, Francia, Gran Bretaña, Italia y España), Ed. Cujas, París, 1982.

70 Vid. sobre esta cuestión I. LOJENDIO: «Los modelos autonómicos de 1931 y 1978. Notas para un paralelo de intenciones, compromisos y fórmulas", Asociación Española de Ciencia Política, Sevilla, 1981. 